\title{
REPENSANDO A ESFERA PÚBLICA: ESBOÇO DE UMA TEORIA CRÍTICA DA DEMOCRACIA*
}

Rúrion Melo

Não há dúvidas quanto à importância do conceito de esfera pública para a teoria social e política da contemporaneidade $^{1}$. E é digno de nota o impacto da formulação que Jürgen Habermas atribuiu a tal conceito desde a década de 1960, especialmente se olharmos para sua recepção nas teorias contemporâneas da democracia e, em particular, para o desenvolvimento da tradição de pensamento conhecida como "teoria crítica". Desde cedo, Habermas deu centralidade ao conceito de esfera pública ${ }^{2}$ e ao longo dos anos não

\footnotetext{
A primeira versão do presente artigo foi apresentada no Seminário de Pós-Graduação do Departamento de Ciência Política da Universidade de São Paulo em abril de 2014. Agradeço a todos os participantes pelas críticas e sugestões, em especial a Adrián Lavalle e Cícero Araújo. Uma versão levemente modificada do artigo também foi discutida no Núcleo Direito e Democracia do Cebrap. Pelos valiosos conselhos e pela leitura atenta, sou grato especialmente a Jonas Medeiros, Denilson Werle, Marta Machado, Gustavo Leyva-Martinez, José Rodrigo Rodrigues e Felipe Gonçalves Silva.

1 Ver o impressionante balanço bibliográfico acerca do conceito de esfera pública em Strum (1994, pp. 161-202). Uma coletânea recente com os textos mais representativos do debate (de Kant às discussões atuais) se encontra em Grisprud et al. (2010).

2 Na verdade, Habermas (1961) já havia empregado o conceito com alguma centralidade em sua pesquisa empírica sobre o movimento estudantil de Frankfurt. É preciso lembrar que, na década de 1950, Habermas participou da pesquisa empírica coordenada por Adorno e Pollock (2011) a respeito da "opinião pública" dos
} 
empregou o conceito da mesma maneira, ainda que sempre reforçasse seu potencial crítico e explicativo ${ }^{3}$.

Não é possível reproduzir com detalhe todo o desdobramento teórico das recepções mencionadas, que atualmente ampliaram o escopo do debate para o âmbito transnacio$\mathrm{nal}^{4}$. Em geral, no que diz respeito às críticas levantadas a Habermas, algumas ressaltam pressupostos históricos insuficientes, outras a dificuldade de concretizar demais o conceito (em que, diante de uma esfera pública "burguesa", se contrapõe uma que inclua os proletários, as mulheres, os negros etc.), e outras ressaltam os riscos de um conceito por demais abstrato ${ }^{5}$. O fato é que podemos compreender melhor as mais diversas tentativas de cobrir os déficits históricos, empíricos ou normativos do conceito de esfera pública, as quais têm sido levadas a cabo na teoria social e política contemporânea, quando estamos cientes do desenvolvimento e das dificuldades que a própria teoria haber12 masiana apresentou ao longo das últimas décadas.

No entanto, minha preocupação teórica, concernente à reconstrução da esfera pública como um conceito crítico, não se restringe à formulação de Habermas. Tal reconstrução

cidadãos alemães no período do pós-guerra em Frankfurt. Nesse mesmo período, Habermas elabora um dos seus mais importantes livros, publicado originalmente em 1962, ancorado em investigações históricas, sociológicas e políticas a respeito do conceito de esfera pública, Mudança estrutural da esfera pública (2014). Para as reações ao livro que marcaram o debate sobre o conceito no final do século XX, ver Calhoun (1992).

3 O conceito de esfera pública permanece presente em toda obra. As referências mais importantes se encontram em Habermas (1981, 1994, 2013, 2014). Para uma discussão normativa sobre o "uso público da razão", ver Habermas (1997); a relação entre razão pública e religião foi abordada principalmente em Habermas (2005). Uma abordagem mais funcionalista da esfera pública, por sua vez, se encontra em Habermas (2008).

4 Esta ampliação é explicitamente tratada em Fraser (2010). Ver ainda Niesen e Herborth (2007), Bohman (2007) e Peters et al. (2009).

5 O livro de Kluge e Negt (1993) certamente foi pioneiro a esse respeito. Em Meehan (1995), encontramos uma crítica baseada na discussão acerca das desigualdades de gênero, e, em Doreski (1999), a partir da questão racial. Para uma discussão em torno do "multiculturalismo" na esfera pública, ver Benhabib (2002, cap. 4 e 5). 
implica repensar o conceito em dois níveis. No primeiro deles, trata-se de identificar os aspectos que, na recepção teórica do conceito habermasiano, foram normativamente sobrevalorizados em mau sentido. Diferentemente de Mudança estrutural da esfera pública (Habermas, 2014 [1962]), em que a análise teórica estava circunscrita ao fenômeno propriamente histórico de formação e decadência da esfera pública burguesa, a formulação habermasiana da década de 1990 seria muito abstrata, com contornos históricos e empíricos pouco definidos. Embora eu acredite que o sentido dessa abstração tenha sido, entre outras coisas, evitar o estreitamento empírico do livro de 1962, pois se pressupunha que, quanto mais abstrato fosse o conceito, mais elementos empíricos ele poderia abarcar, é sua consequência no debate pós-habermasiano que me interessa particularmente. Em Faktizität und Geltung (Facticidade e validade) (de 1994), sobretudo, haveria uma confusão entre a reconstrução dos procedimentos comunicativos elaborados pela teoria do discurso (aliás, único recurso teórico capaz, nos termos habermasianos, de constituir um referencial normativo) e o papel social da esfera pública. Não por acaso, as críticas que se seguiram ao livro procuraram enfatizar e rever ora o que seriam os princípios e modelos normativos pressupostos naquela exposição específica do conceito, ora insistir que tal conceito seria insuficiente para ancorar socialmente o ponto de visto crítico da teoria.

Porém, fica a pergunta: por que o próprio Habermas nunca empregou o conceito de esfera pública como uma categoria estritamente normativa? Porque o empregou, com maior ou menor êxito, por assim dizer, como uma categoria crítica. Mais especificamente, Habermas nunca considerou que o conceito de esfera pública fosse puramente normativo porque o discerniu antes de tudo na qualidade de "fenômeno social elementar" (1994, p. 436), ligado ao espaço social e composto por uma estrutura comunicativa 
(experiências práticas, organizações sociais, estruturas simbólicas, reprodução da cultura política). Esse discernimento pode ser aproveitado (e levado adiante certamente para além dos próprios escritos de Habermas) se a esfera pública for compreendida como ponto de partida para a reconstrução de categorias crítico-normativas, não como ponto de chegada. Ou seja, ela mesma não é modelo, princípio ou conceito normativo por excelência, já que somente engendra do interior de um espaço social aberto e dinâmico (geralmente em disputa) o referencial normativo reconstruído pela teoria.

Além disso, há um segundo nível de reconstrução em que tais pressupostos metodológicos de fundo são "testados", tendo em vista o propósito mais geral de identificar os potenciais emancipatórios inscritos na realidade social. Em função deste propósito, partilho de uma hipótese ampla no que diz respeito aos pressupostos normativos atribuídos 14 geralmente ao conceito e que concernem à crítica do poder e aos critérios de legitimação -, de acordo com a qual determinados processos políticos e sociais que adentram a esfera pública - e trazem consigo transformações nas instituições, atores e práticas correspondentes - nos permitem entrever uma tendência de democratização. Se olharmos para a relação entre política e direito, essa democratização adquire um sentido bem específico. A mobilização política dos cidadãos não se encaixa simplesmente no esquema de uma luta contra o sistema político (ou mesmo econômico). Impulsionados por razões morais, éticas ou meramente estratégicas (sem entrar aqui no mérito a respeito de suas causas e motivações individuais, que precisam ser empiricamente verificadas a cada vez), os cidadãos são capazes de aumentar seu poder de influência, colocando em marcha uma tendência de transformação da relação entre Estado e sociedade juntamente com a ampliação de espaços potencialmente democráticos de participação política. Esses conflitos colocam 
um desafio para a democracia atual e fundam o horizonte a partir do qual os obstáculos existentes são diagnosticados e os conceitos críticos engendrados. O conceito de esfera pública ajuda-nos a elucidá-los teoricamente ${ }^{6}$.

Os movimentos sociais e a sociedade civil organizada têm tornado o sistema representativo mais reflexivo, influenciando, por exemplo, processos legislativos e decisões do Judiciário. Eles simultaneamente modificam os sentidos da emancipação e apresentam uma atitude crítica diante do presente: não se luta "contra" a democracia e o direito, ou simplesmente "ao lado" deles, mas por mais direitos, mais pluralização da representação e pela radicalização da democracia (cf. Melo, 2013). Essa perspectiva crítica está amplamente presente nas pautas político-jurídicas atuais, com a ideia do pluralismo jurídico, das transformações da cidadania e da representação política, da reforma do Judiciário e mais acesso à justiça, das ações coletivas e das tematizações públicas ligadas às reivindicações em torno de desigualdades e diferenças ${ }^{7}$.

Minha hipótese é a de que esses dois níveis de análise juntos permitiriam assim uma composição equilibrada

\footnotetext{
6 Evidentemente o conceito de "sociedade civil" ainda é central. As referências teóricas mais importantes continuam sendo Arato e Cohen (1992) e Keane (1988). No que diz respeito, porém, ao problema do caráter ainda fortemente normativo dos princípios de unificação da sociedade civil, penso ser melhor seguir, por razões tanto genéticas quanto analíticas, o esquema proposto e a preocupação contra uma despolitização do conceito tal qual apresentado em Lavalle, Castello e Houtzager (2011). Para um balanço sobre os desdobramentos do papel da sociedade civil a partir dos anos 1990, ver ainda Lavalle (2003).

7 Para uma visão esquemática dessa perspectiva de institucionalização como indício de demandas pela democratização das instituições formais, ver Costa, Melo e Silva (2009). No caso da relação entre racismo e esfera pública, ver, especialmente, as pesquisas-piloto em Costa et al. (2011) e Machado, Rodriguez e Püschel (2011). Para a pesquisa em torno de gênero (baseada nos processos da Lei Maria da Penha), ver Machado et al. (2013). Para as questões de acesso à justiça, ações coletivas e reforma do Judiciário, ver também o conjunto de artigos sobre "direito, sociedade e Estado", publicados em Rodriguez e Silva (2013). Estudos recentes, em que são abordadas amplas experiências de participação dos movimentos sociais na esfera pública no Brasil, se encontram em Lopes e Heredia (2014).
} 
entre categorias teóricas e diagnóstico de tempo, uma preocupação com o caráter reconstrutivo dos referenciais crítico-normativos tanto quanto dos contextos sociais e políticos em disputa ${ }^{8}$. Essa reconstrução obriga a teoria, portanto, a manter um constante vínculo com a práxis política dos cidadãos, a atentar para a produção imanentemente política de critérios de legitimidade e, desse modo, a relacionar seus diagnósticos (e, por conseguinte, sua própria perspectiva crítica) às pesquisas sociais empiricamente orientadas. Em suma, a reconstrução lança o teórico no espaço social e político em questão, exigindo uma renovação dos diagnósticos e também das próprias categorias normativas produzidas. Para uma teoria crítica da democracia, uma descrição adequada dos processos acima mencionados deve servir para retirar de dentro deles potenciais e tendências a serem explorados em termos práticos, que podem ou não ser aproveitados, evitando que princípios normativos externos 16 preencham a priori as lacunas do diagnóstico. Do mesmo modo que nos força a reconhecer os limites da teoria que, diante da vida política, também precisa deixar nas mãos dos próprios concernidos a condução consciente e autônoma de seus problemas. Essa "indeterminação do político", por assim dizer, faz parte da gênese de critérios críticos na medida em que muitas das questões enfrentadas exigem não uma tarefa teórica, mas, sobretudo, prática.

Apresento aqui alguns indícios de como o conceito de esfera pública pode ser pensado tendo em vista os dois níveis de reconstrução mencionados. Por razões esquemáticas, na primeira parte me restrinjo a levantar algumas dificuldades metodológicas que o conceito de esfera pública seria capaz de sanar quando o consideramos "contexto de surgimento" adequado de categorias crítico-normativas.

\footnotetext{
8 Para a compreensão da teoria crítica como "teoria reconstrutiva da sociedade", ver Nobre e Repa (2012). Sobre as implicações da "reconstrução" para uma teoria da democracia, ver ainda Melo e Silva (2012).
} 
$\mathrm{Na}$ segunda parte, por fim, aponto o que entendo ser o potencial explicativo do conceito. Não se trata de utilizá-lo de modo a antecipar resultados de processos em curso a serem investigados. Ele serve antes para identificar entraves e formas de patologias sociais, cujas consequências práticas podem indicar processos de tematização, participação e institucionalização de demandas sociais. Desse modo, voltamo-nos para a esfera pública menos para replicar um determinado ethos democrático normativamente carregado, e sim para diagnosticar experiências práticas de desigualdade, exploração, exclusão e desrespeito que ganham uma configuração política e colocam em circulação o poder. Pretendo testar minha hipótese olhando para a relação entre política e direito, mais especificamente para as pesquisas que investigam processos de institucionalização, cujo sentido aponta para a democratização de instituições formais do sistema político. Das patologias e conflitos diagnosticados até os processos colocados em movimento, o conceito de esfera pública apresenta um potencial explicativo repleto de consequências. Contudo, também esse segundo nível levanta mais questões e hipóteses de investigação futura do que apresenta resultados concretos abrangentes.

\section{Reconstrução da esfera pública como conceito crítico}

É sintomático que o debate em torno do conceito habermasiano de esfera pública, concentrado, conforme mencionado, nos "déficits sociológicos" de sua abordagem normativa, tenha reforçado dois aspectos teóricos aparentemente concorrentes: a reconstrução da esfera pública como categoria normativa ou empírica. Uma ampla literatura tem reforçado o teor normativo vinculado aos princípios morais que tal esfera pressupõe (publicidade, justiça, reciprocidade, igualdade, equidade), aos valores solidários, éticos e comunitários que a impregnam, à ação cooperativa e reflexiva na construção da vontade pública e da autorrealização indi- 
vidual, às práticas deliberativas e participativas que a constituem. Independentemente de saber se tais características contam com um recorte universalista ou comunitarista, liberal ou republicano, é possível afirmar que todas essas abordagens procuram ressaltar o viés potencialmente democrático do conceito de esfera pública ${ }^{9}$. De outro lado, porém, explicações com apelos mais sociológicos e empíricos apresentaram interpretações que foram disputadas por correntes realistas e funcionalistas, em que o espaço público é configurado pela dominação social e política (elitista, classista, conservadora, anárquica), pela "razão instrumental" de um Estado altamente burocratizado e de uma "indústria cultural" reificante, esfera de uma formação não esclarecida da opinião e, portanto, pouco democrática ${ }^{10}$.

De fato, essa caricatura, em que estamos diante de duas faces opostas da esfera pública (uma potencialmente democrática e outra não), foi recusada por muitos dos autores 18 anteriormente considerados. Muito mais interessante é perceber as contradições ou tensões apontadas nos pressupostos dos conceitos que a categoria é capaz de englobar. Quando falamos de esfera pública, trata-se de questionar antes sua abrangência e potencial inclusivo, saber quem pode realmente participar da formação porosa da opinião pública, ou seja, disputar - com uma sensibilidade ao contexto - os teores normativos assumidos pelas teorias. E isso

\footnotetext{
9 Além de Habermas, incluem-se ainda Rawls (2007), O’Neil (1990), Bohman (1996), Fraser (1992) e Benhabib (1992a). Abordagens mais hegelianas se encontram em Taylor (2000) e Honneth (2000a, 2011). Além de Arendt (2009), uma referência central é o livro de Dewey (1954). Considerações mais reflexivas e sociológicas do teor normativo do conceito podem ser vistas em Arato e Cohen (1992) e Peters (2007a). Para uma reconstrução da discussão do pano de fundo normativo, ver Forst (2010) e Melo (2011).

${ }^{10}$ Os trabalhos de Lippmann $(1993,2012)$ e Mills (2000) foram decisivos para esse tipo de abordagem. Outra referência importante para entender essa concepção de esfera pública continua sendo aquela derivada do conceito de "indústria cultural" elaborado por Adorno e Horkheimer (1985). Sem tirar conclusões tão pessimistas, ver também Thompson $(1990,1995)$.
} 
sempre nos lança à gênese das categorias teóricas reconstruídas a partir de processos políticos efetivos.

Pretendo compreender de que maneira ocorre na esfera pública a junção desses dois aspectos, os quais não deveriam ser separadamente considerados (cf. Peters, 2007b, 2007c; Habermas, 2008). A descrição das disputas e questões que adentram a esfera pública deve permitir a cada vez a reconstrução de categorias críticas que lhes são imanentes. Dessa forma, com a reconstrução da esfera pública é possível explicitar a gênese das categorias críticas (sempre atreladas a diagnósticos de tempo em disputa, vale lembrar, na própria esfera pública), abrangendo o vínculo entre movimentos sociais, esferas públicas formais e informais e cultura pública de fundo. Trata-se de recusar assim o dualismo estanque "normativo-empírico" muitas vezes pressuposto por aqueles que procuram ressaltar as diferenças entre potenciais de libertação e bloqueio na esfera pública. Práticas informais de formação da opinião, distinções espaciais, modos de auto-organização, configuração institucional, processos de autodeterminação, reprodução cultural e sistema midiático - elementos que não devem nem ser normativamente neutralizados de antemão, nem sobrevalorizados em termos normativos.

No entanto, embora pensado de modo a evitar a mera oposição entre seus aspectos normativos e empíricos, o conceito de esfera pública ainda deveria ser capaz de responder a seis objeções centrais já levantadas contra sua formulação em termos habermasianos.

Déficit sociológico e superação do dualismo. Trata-se de repensar os fundamentos normativos da crítica a partir da dinâmica social efetiva, superando tanto a distinção entre "sistema" e "mundo da vida", juntamente com a concepção de racionalidade pressuposta, quanto a ideia de uma intersubjetividade comunicativa orientada para o entendimento linguístico (cf. Honneth, 1985, 2000b; Celikates, 2009). Isso 
teria impossibilitado Habermas de pensar os próprios sistemas e a sua lógica instrumental como resultado de conflitos sociais permanentes. Como consequência, no modelo de teoria crítica formulado por Habermas, a dinâmica de transformação e as patologias sociais passam a ser descritas de forma muito abstrata, mecânica e funcional, como processos de racionalização que decorrem de um embate entre imperativos sistêmicos colonizadores e as estruturas intersubjetivas comunicativas do mundo da vida. Segundo a interpretação oferecida por Honneth, o paradigma da comunicação teria de ser desenvolvido não nos termos de uma teoria da linguagem, mas a partir das relações de reconhecimento formadoras da identidade, isto é, da constituição intersubjetiva da identidade pessoal e coletiva. Ora, é antes a partir dos sentimentos de injustiça e desrespeito decorrentes dessas pretensões de identidade individual e coletiva que a dinâmica da reprodução social, dos conflitos 20 e da transformação da sociedade poderiam ser mais bem explicados, sem abdicar dos fundamentos normativos da crítica. Com isso, mudaria o ancoramento da teoria crítica na realidade social ${ }^{11}$.

Poder e patologia. O diagnóstico crítico de nossa época teria de ser deslocado. Novamente segundo Honneth, em vez de focalizar a tensão entre sistema e mundo da vida, a perspectiva crítica deveria se concentrar nas causas responsáveis pela sistemática violação das condições de reconhecimento. O critério para identificar as patologias sociais não residiria mais nas condições racionais da busca por um entendimento livre de dominação, mas, sim, seria fornecido pelos pressupostos intersubjetivos da formação bem-sucedida da identidade humana, na luta por reconhecimento e suas

\footnotetext{
${ }^{11}$ Isso remeteria a uma nova maneira de entender a relação entre interação social e a "gramática moral dos conflitos sociais" (cf. Honneth, 2003). Para uma interpretação crítica acerca da centralidade do paradigma da "luta" no quadro da teoria do reconhecimento, ver Melo (2014).
} 
configurações sociais e institucionais (isto é, no âmbito do "social"). Em suma, seria necessário assim olhar para relações de poder no interior das interações culturais e sociais enquanto tais, entendendo as tensões e patologias impregnadas nas próprias "formas de vida" 12 .

Outro generalizado e outro concreto (justiça e bem). Crítica à universalização de procedimentos intersubjetivos em que os participantes dos discursos são concebidos meramente como pessoas morais com capacidades racionais iguais, sem levar em consideração as pessoas em sua singularidade, suas disposições individuais, carências, desejos e concepções de bem. Desse modo, critérios normativos de crítica social, com amplas consequências políticas, deveriam ser sensíveis ao ponto de vista do "outro concreto", considerar o indivíduo com uma história e identidade concretas, com uma constituição afetiva e emocional (cf. Benhabib, 1992b).

Autonomia privada e pública (inclusão x exclusão na esfera pública). Teorias universalistas, que negligenciam interações morais e sociais com o "outro concreto", tendem a cristalizar barreiras entre esfera privada e pública. A neutralidade diante de concepções de bem e justificações axiológicas limitam a agenda e o escopo da "razão pública", cuja consequência política foi a exclusão da esfera pública de grupos tais quais mulheres e negros. A redefinição da relação entre "justo" e "vida boa" no processo democrático tem reflexo nos contornos entre público e privado, permitindo a inclusão da perspectiva daqueles excluídos da deliberação pública (limitados ao âmbito do privado, como no caso das mulheres) (cf. Young, 1990; Benhabib, 1992a; Fraser, 1992).

Eticidade democrática. Expectativas normativas (reconstruídas pela teoria) são parte, na verdade, de um conjunto de valores centrais que orientam as práticas privadas e

12 A junção entre a tradição da teoria crítica e Foucault já foi apontada em Honneth (1985). Críticas semelhantes se encontram em Fraser (1989, 2013) e também em Jaeggi (2013). 
públicas dos sujeitos. Experiências patológicas (desrespeito, humilhação, exclusão, discriminação, exploração) são avaliadas de acordo com princípios éticos e morais profundamente arraigados na cultura política democrática da modernidade. Mas quando se entende que tais valores modernos giram em torno da liberdade, igualdade, dignidade, respeito e justiça, percebe-se que não conservam costumes, hábitos e valores cristalizados e naturalizados. São fundamentalmente reflexivos. Isso caracteriza a pressuposição de uma "eticidade democrática" (chamada também de "eticidade pós-convencional”), em que aspectos universalistas se mantêm sensíveis aos contextos sociais e culturais modernos (cf. Benhabib, 1992c; Honneth, 2011) ${ }^{13}$.

Deliberação, conflito e disputa. A ideia reguladora, segundo a qual discursos racionais se orientam pelo entendimento, levar-nos-ia equivocadamente a conceber a deliberação pública como um processo consensual. Por conseguinte, a 22 esfera pública também seria pensada de forma equivocada como uma dimensão do consenso. Interações sociais e práticas políticas são compostas, antes, por conflitos de valores e interesses (muitas vezes inconciliáveis). O critério normativo de uma justificação consensual (fruto do "procedimentalismo") não poderia passar por cima da característica conflituosa de processos deliberativos também presentes nas democracias. As deliberações são processos "em aberto", que não almejam um resultado comum (consenso "cognitivo" fundado em razões), mas concernem ao andamento de negociações práticas (cf. McCarthy, 1991; Walzer, 2007; Bohman, 1996).

Habermas reagiu de maneira mais ou menos explícita a uma série dessas críticas ${ }^{14}$. Penso que possamos refletir

\footnotetext{
13 Uma referência para este tipo de abordagem está muito vinculada a Rawls (2011). Para uma análise do "ethos democrático" no debate entre liberais e comunitaristas, ver também Forst (2010, cap. 3).

${ }^{14}$ É digna de nota a mudança operada entre a elaboração de sua "ética do discurso"
} 
melhor a respeito dos problemas levantados por tais críticas se nos voltamos novamente para o conceito de esfera pública, retirando dele muito do que foi ofuscado e negligenciado. Em todo caso, tais críticas podem nos orientar a articular certas contribuições que já estão presentes em Habermas com as preocupações concernentes ao ancoramento social da crítica. Porém, se, de um lado, há um visível movimento da teoria crítica em compreender a gênese das categorias críticas com base na reconstrução de experiências pré-teóricas e inscrever suas pretensões normativas fundamentalmente nas interações sociais (no domínio amplo e paradigmático para a teoria crítica pós-habermasiana do que Honneth entende por "social”), de outro lado, a dimensão conflituosa intrínseca a tais relações, bem como a elucidação dos contextos de surgimento baseados em diagnósticos de tempo parecem ter diminuído seu papel central na fundamentação dos conceitos críticos utilizados. Portanto, o conceito de esfera pública colocado em discussão atualmente, voltado à reconstrução da gênese prático-política de fundamentação de tais conceitos, pode ser compreendido a título de politização do social.

Do ponto de vista reconstrutivo, portanto, a "politização do social”, tornado possível pelo conceito de esfera pública, é capaz assim de descortinar experiências práticas que estão na base das ações políticas. O discernimento de Habermas desde Mudança estrutural da esfera pública (presente paradigmati-

(com pretensões fortemente universalistas) na década de 1980 e sua "teoria dos discursos" formulada cerca de dez anos depois, 1994, em Faktizität und Geltung (Facticidade e validade), tornando possível: incorporar elementos éticos, pragmáticos e morais no interior do procedimento de aceitabilidade racional e justificação normativa reconstruído nos discursos; fundamentar critérios de legitimação abertos a uma deliberação política abrangente (falsamente interpretada, aliás, como processo baseado no consenso); e voltar-se às pautas do reconhecimento (principalmente no caso das críticas comunitaristas e feministas). Certamente sua exposição da esfera pública se alterou também em decorrência de algumas dessas mudanças de fundamentação. Para uma problematização dessas mudanças, ver Melo (2011). 
camente em Thompson (1993, 2002), Kluge e Negt (1993); e Calhoun (1982, 2012) é o de que práticas vinculadas à cultura, identidade e comunidade foram importantes para a formação política das sociedades ocidentais. É preciso assim se debruçar na articulação de tais experiências práticas (que subjazem à cultura política de fundo) e os modos de atuação dos movimentos sociais e da sociedade civil, práticas deliberativas, mobilizações públicas, estratégias de influência e pressão sobre o Estado.

Portanto, com base principalmente na análise crítica do conceito de esfera pública em Habermas, e compreendendo as diferentes formulações expostas ao longo de sua obra, será possível identificar as críticas ao déficit tanto normativo quanto social a tal conceito e sistematizar os seguintes aspectos que ancoram o desenvolvimento de sua reconstrução. O conceito de esfera pública:

(a) pode evitar a "neutralização sistêmica" (efeito colateral 24 do dualismo habermasiano), pois assume que os efeitos patológicos criados pela intervenção do Estado e da economia tem uma gênese política e social. Nesse caso, pressupõe-se que o paradigma sistêmico (geralmente empregado para se pensar dimensões não normativas, características do poder e práticas heterônomas) não tem origem funcional, nem pode ser medido apenas com o conceito de "forma de vida" (a ideia, por exemplo, do capitalismo como forma de vida, dimensão de interação ética e moral, espaço de autorrealização e liberdade). Trata-se antes de pensar que seus efeitos patológicos podem ser reconstruídos a partir dos processos políticos que estão na sua base (em termos tanto genéticos quanto analíticos);

(b) pode elucidar de que maneira categorias críticas possuem uma gênese político-social - isto é, que conceitos críticos tais como "reconhecimento" e "autonomia" descrevem e caracterizam, se for o caso, o sentido real 
das lutas e conflitos na esfera pública, os quais podem ser então reconstruídos e assim interpretados normativamente. Essa gênese está necessariamente ligada à formação de uma cultura política que a "esfera pública" pode elucidar em toda sua complexidade. Modelos normativos muito abstratos - liberal, republicano, conservador -, embora teoricamente importantes para dar sentido e organizar a experiência, tendem a perder os detalhes dos processos;

(c) vincula formas de poder e fenômenos patológicos às relações sociais e culturais abertas e engessadas no entrelaçamento das esferas privada e pública. De um lado, interações concretas que formam a vida cotidiana (gostos culturais, estrutura familiar, sexualidade, escola, religião etc.) determinam padrões de formação da opinião e relações de poder. De outro, são elucidados aí os contextos concretos de interação, formas solidárias de socialização baseadas em tradições culturais comuns, isto é, redes de relações sociais comprometidas reflexivamente a determinadas formas de vida;

(d) não deve ser considerado uma dimensão do "consenso”. Pelo contrário. É na esfera pública que dimensões de conflito tornadas historicamente relevantes foram geradas e se desdobraram em processos amplos de luta, conquistas e derrotas (cidadania, direitos, representação, participação). Nela se evidenciaram a consciência política da sociedade civil burguesa, a exploração dos trabalhadores, a exclusão das mulheres, a discriminação dos negros. Nela se formaram politicamente ideais de liberdade, igualdade e inclusão (que orientaram, nunca sem disputas, processos revolucionários históricos), mas também uma esfera pública nacional de cunho "naturalista", com consequências altamente excludentes e racistas (como no caso da experiência nacional-socialista). Trata-se de um campo de disputa com papéis políticos 
decisivos, mas que, em termos tanto históricos quanto espaciais, foram desempenhados de maneiras diferentes. É um espaço social conflituoso em que relações de poder que perpassam a experiência prática e a vida cotidiana trazem consequências para a esfera pública, podendo gerar tematizações públicas amplas e organizadas, manifestações de revoltas difusas e, se for o caso, impor transformações institucionais importantes. Se uma reflexão sobre tal conceito pretende manter o propósito crítico de sua gênese, sua reconstrução precisa vincular o horizonte normativo necessariamente com as práticas e experiências, conflitos e lutas que subjazem aos contextos diversos de nossa cultura política democrática;

(e) por fim, a esfera pública expõe de forma dinâmica processos abrangentes que constituem os diagnósticos de tempo. Entram em cena novos fenômenos e questões que a esfera pública é capaz de abranger - pluralização da sociedade civil, ambientalismo, movimentos negros, feminismo, movimentos homossexuais, conflitos urbanos etc. É possível assim conceber na esfera pública um forte impulso autonomista dos movimentos sociais e da sociedade civil organizada com a finalidade de democratizar as instituições formais, colocando no centro do diagnóstico do presente, portanto, as relações entre política e direito. Este aspecto já nos lança em direção ao segundo nível de reconstrução.

\section{Esfera pública e circulação do poder}

O segundo nível de reconstrução - que não pode ser levado a cabo apenas do ponto de vista dos modelos normativos em disputa pelas diferentes teorias políticas e sociais - deve nos permitir esboçar os contornos de uma possível concepção de esfera pública que tenha potencial explicativo, mas que ainda seja passível de produzir referenciais normativos (considerando que o propósito crítico da teoria não se limi- 
ta à descrição, embora não possa prescindir desta). Tal concepção pressupõe uma série de processos históricos (por vezes ambivalentes), que não poderei abordar no presente artigo, os quais implicam (a) a constituição de um espaço sintomático de conflito e de encarnação da liberdade política; (b) a configuração histórica do Estado de direito (em seu domínio nacional e transnacional); e (c) estruturas sociais e simbólicas tais quais as formas de "auto-organização" política associativas e civis, bem como uma ampla rede de comunicação possibilitada pelas mídias de massa ${ }^{15}$.

Limito-me aqui a destacar uma concepção de esfera pública (nunca isenta de verificação empírica) em que a perspectiva crítico-normativa adotada encontra sua gênese no interior de um processo de circulação do poder. Esse processo, cujo perfil será determinado no presente artigo pela relação entre política e direito, aponta para formas de auto-organização social com uma dinâmica peculiar, permitindo à teoria crítica diagnosticar os riscos do engessamento democrático: de um lado, sem desprezar os procedimentos formais de organização institucional do poder político (regra da maioria, eleições periódicas, divisão de poderes), diagnostica que não é mais possível encapsular a vida democrática nas instituições do sistema político; de outro, ao valorizar práticas autônomas de auto-organização, sublinha os potenciais e entraves políticos presentes na dinâmica de esferas públicas. $\mathrm{O}$ aprofundamento da democracia depende assim do diagnóstico acerca da vitalidade da esfera pública política ${ }^{16}$.

${ }^{15}$ Habermas (2014) continua sendo referência importante para a compreensão dos processos históricos mencionados. Atualmente, Honneth (2011) procurou reunir explicitamente essas três dimensões ao expor o seu próprio conceito de "esfera pública democrática".

${ }^{16}$ Embora este segundo nível de reconstrução esteja mais voltado na presente exposição para a capacidade de influência da sociedade sobre as instituições políticas, é preciso deixar claro que a esfera pública não esgota seu potencial democrático do ponto de vista da "institucionalização". Antes, a esfera pública, por definição, não se reduz ao âmbito institucional, constituindo-se principalmente como dimensão social de auto-organização. 
Há uma normatividade latente quando compreendemos a esfera pública como um espaço social de circulação do poder. Essa ideia, que Habermas incorpora na década de 1990 a partir dos estudos de Bernhard Peters, é passível de ser operada em pesquisas sociais abertas. Por sua vez, ela não depende de critérios normativos substantivos anteriores (valores éticos ou morais, liberais ou republicanos etc.), ainda que permita gerar conceitos normativos geneticamente fundamentados (por exemplo, podemos testar ao final se conceitos como "autonomia" ou "reconhecimento" servem para interpretar criticamente os fenômenos em questão). Ela denota antes um processo de influenciação recíproca entre as práticas dos cidadãos e o modo de operar do sistema político. E pressupõe (de maneira empiricamente apoiada) que temas controversos (decorrentes de experiências práticas social, cultural e politicamente produzidas) podem colocar em movimento uma ampla circulação do poder ${ }^{17}$. Em outros 28 termos, a esfera pública pode descrever as mediações entre fenômenos práticos do espaço social e as decisões e modos de atuar das autoridades estatais, isto é, a dinâmica de processos democráticos ${ }^{18}$.

\footnotetext{
${ }^{17}$ Experiências práticas patológicas desencadeadas em dimensões múltiplas (com ou sem intersecções): desigualdades econômicas, sociais e regionais; discriminação de gênero, raça, sexo, origem, língua; violência urbana; exclusão política; violação de direitos humanos e fundamentais (civis, políticos, sociais) etc. A lista certamente pode ser incrementada. Temos acesso a tais fenômenos de maneira cotidiana pela mídia de massa. Mas também precisamos estabelecer temas e ações presentes olhando, de um lado, a pauta dos movimentos sociais e da sociedade civil, suas novas formas de atuação na esfera pública informal e também nos âmbitos que estruturam o entorno do sistema político (evidenciadas em ações jurídicas de diversas ordens); e, de outro, avaliando as instâncias formais (por exemplo, os processos legislativos, as decisões no Judiciário). Sem dúvida, estamos diante de interesses muito mais amplos que não podem ser politicamente desconsiderados. $\mathrm{Na}$ literatura internacional recente, ver a rica e complexa relação de grupos da sociedade civil organizada com representantes do sistema político e membros dos setores econômicos, apresentada na pesquisa de casos norte-americanos em Lang (2014).

18 Para o tema da "mediação", partimos do modo como Arato e Cohen (1991) compreendem o papel da esfera pública na articulação entre Estado e sociedade civil.
} 
As determinações conceituais da esfera pública se deixam notar nos processos de formação política da opinião e da vontade, em que se entrecruzam os procedimentos de deliberação pública juntamente com a dinâmica da circulação do poder político. Nos trabalhos de Peters, encontram-se articulações teóricas e descrições empíricas ricas para a análise dos discursos públicos, das funções, potenciais e níveis de racionalidade presentes nos procedimentos de deliberação pública, da capacidade de reprodução cultural e da formação de uma cultura pública, dos processos de aprendizado, dos aspectos dinâmicos dos mecanismos de seleção de temas e contribuições, bem como dos processos de integração social e de legitimação política centrados na esfera pública (cf. Peters, 1992, 2007a). A tematização pública revela uma estrutura simbólica ilimitada, que transita entre os aspectos normativos dos discursos racionais, deliberações e justificações da legitimidade até mobilizações não discursivas, tipos e gêneros de atividades sociais e culturais, e cultura de fundo (cf. Peters, 2007c, pp. 103-05). Já as distinções empíricas que o conceito abrange incluem estruturas sociais e funções da esfera pública, tais como as categorias de participação, estruturas de produção e criação de meios de comunicação, segmentação e estratificação social, diferenciações entre esferas públicas nacionais e a existência de esferas públicas transnacionais (cf. Peters, 2007d, pp. 28396). Desse modo, a circulação complexa do poder político envolveria a deliberação pública (em esferas públicas formais e informais) ${ }^{19}$, assim como uma cultura pública (em que se identificam e colidem valores e temas comuns, imagens familiares à cultura de fundo - expressas em filmes,

\footnotetext{
${ }^{19}$ Habermas incorpora ao modelo de circulação de poder de Peters a diferenciação proposta por Fraser (1992) entre esferas públicas formais e informais. Contudo, segundo Scheuerman (2002), não seria possível articular ambas as perspectivas (de Peters e de Fraser) em uma concepção coerente de esfera pública. Procurei matizar as críticas de Scheuerman em Melo (2013, cap. 6).
} 
música, teatro, literatura, jornais, televisão, internet etc. -, o público de especialistas, a percepção de um horizonte histórico e espacial comum, a elaboração de convicções, os laços culturais das tematizações que se transformam em opinião pública).

A própria deliberação pública pode ser reconstruída em razão dos procedimentos democráticos e da diferenciação interna de seus discursos, ou de acordo com os deslocamentos temáticos e participativos colocados em circulação no processo de formação da opinião e da vontade. Isso porque as tomadas de decisão política pretensamente legítimas geralmente são precedidas pelos fluxos comunicativos gerados em esferas públicas informais, e estas, por seu turno, podem qualificar e influenciar o conjunto de justificação das corporações parlamentares, do Judiciário etc. (cf. Costa et al., 2011). Certamente que esse modelo de circulação do poder pressupõe um processo complexo e dinâmico perme30 ado não apenas pela luta social e pela esfera pública, mas também pela interdependência e constituição recíproca entre política e direito. É decisivo entender que, quando olhamos para a circulação do poder, não se trata de simplesmente alojar o conceito de esfera pública no quadro institucional. Por lançar luz sobre os processos políticos em sentido alargado, temos de abarcar experiências da cultura política amplamente consideradas, ou seja, pensar a mediação junto com estruturas periféricas e processos informais de formação da opinião, criando assim um espaço em que se produzem convicções, articulam-se temas ou problemas, e decisões são tomadas. Pois embora, sob certos aspectos teóricos, os sistemas de ação funcionalmente especializados possam ser analisados como se independessem da interação social, os meios de regulação continuam ancorados no componente social e cultural da sociedade.

Peters, seguido de perto por Habermas, forneceu ainda um modelo de circulação do poder entre centro e periferia, no 
qual descreve a possibilidade e os limites da assimilação dos conflitos na articulação entre ação social e sistema político (cf. Peters, 1992; Habermas, 1994). A novidade do modelo consiste em mostrar, primeiramente, que o centro (em que se encontram a administração, o Judiciário e as muitas corporações parlamentares, eleições políticas, concorrência entre partidos etc.) se ramificaria de acordo com a capacidade de ação e a densidade da complexidade organizatória, tais como a percepção e a tematização de problemas sociais (cf. Peters, 1992, pp. 330-36). E essa descrição do funcionamento e das atividades ramificadas já abrangeria, além disso, estruturas intermediárias de organização, ou seja, estruturas periféricas, entre as quais se incluiriam os

[...] processos de formação política da opinião e da vontade e as correspondentes estruturas institucionais (partidos e outras organizações), atividades jurídicas além daquelas do Legislativo e do Judiciário (a ciência jurídica, consultoria jurídica, firmas de direito privadas) ou os papéis dos grupos de interesse em face da administração e do parlamento (Peters, 1992, p. 337; tradução do autor).

Tais estruturas intermediárias têm uma função de articulação de problemas e formulações de políticas que competem ao espectro de partidos, grupos de interesse e movimentos sociais, os quais também se diluem no âmbito da opinião pública ou se condensam na esfera pública política através de meios de comunicação de massa, pesquisa de opinião, uma multiplicidade de redes de comunicação e públicos que se cristalizam em temas e publicações atuais, contextos de discussão determinados etc. (cf. Peters, 1992, pp. 339-40).

Os processos de comunicação e de decisão do sistema político são descritos por Peters segundo a imagem de um modelo de eclusas. As eclusas funcionam, na verdade, como um sistema de comportas que podem ser transpostas, permitindo 
a interconexão entre o núcleo institucional e os influxos da periferia procedentes da esfera pública. As comportas representam, no modelo de eclusas, barreiras e estruturas de poder presentes na esfera pública e nos centros de poder político, as quais, para serem superadas, dependem das mobilizações e manifestações de revolta que, em certo momento crítico, atingem um grau de tal modo intenso na esfera pública, a ponto de modificar as relações de força entre a sociedade civil e o sistema político; e também da possibilidade que o próprio Estado de direito possui para regular os fluxos de poder que atravessam tal sistema. Em todo caso, afirma Peters,

[...] a legitimidade das decisões depende dos processos de formação da opinião e da vontade na periferia. O centro é um sistema de comportas a ser atravessado por muitos processos no âmbito do sistema jurídico-político, mas o centro controla a direção e a dinâmica desses processos apenas de forma limitada. As mudanças podem partir tanto da periferia quanto do centro, e se pode também deixar de sempre atribuir ao centro institucional um primado causal nesse percurso. Muitas modificações do direito, por exemplo, produzem-se essencialmente nas estruturas informais da periferia, na forma de mudanças na consciência jurídica ou das práticas correspondentes - mudanças que precisam ser ratificadas no fim pelas instituições autorizadas. A ideia de democracia repousa, em última instância, no fato de que os processos de formação política da vontade, que no esquema aqui esboçado possuem um status periférico e intermediário, devem ser decisivos para o desenvolvimento político (Peters, 1992, pp. 340-41; grifo no original; tradução do autor).

O modelo de circulação do poder sugerido por Peters possibilita descrever e analisar a dinâmica dos debates e conflitos desencadeados em arenas formais e informais de 
discussão no quadro do Estado constitucional e das democracias de massa, permitindo entender como, a partir da participação em tais debates, movimentos sociais, por exemplo, podem exercer influência sobre o processo legislativo, as ações do Executivo ou a maneira como determinada norma ou lei é interpretada no âmbito do Judiciário. Esse processo de influência, fundamental para entender as lutas por emancipação, percorre a formação da opinião em espaços públicos informais (nas quais questões controversas passam a ser tematizadas publicamente), adentram as arenas formais de deliberação (onde determinados temas são sistematizados na legislação), chegando também à esfera de aplicação no Judiciário e na administração. Nesse caso, a circulação de poder na esfera pública seria constituída, portanto, a partir de uma relação de mão dupla entre centro e periferia - e isso tanto entre o processo legislativo e as discussões públicas (na medida em que o Legislativo pode reagir aos debates públicos e os processos legislativos podem criar ondas de discussão de temas diversos no âmbito da esfera pública) ou nas relações entre a esfera pública e o Executivo, esfera pública e Judiciário ${ }^{20}$.

$$
* * *
$$

Repensar a esfera pública significa, no contexto do presente artigo, trazer à tona seu potencial teórico-analítico tanto quanto seu propósito crítico-normativo. Procurei ressaltar inicialmente que, a despeito das dificuldades apresentadas na formulação habermasiana, é ainda frutífero revistá-la. Para tanto, porém, não podemos reconstruir o conceito de esfera pública como um modelo ou princípio normativo regulador abstraído do espaço social efetivo. Tal conceito se

\footnotetext{
${ }^{20}$ A esse respeito, ver Costa, Melo e Silva (2009, p. 211 e ss.), e também Machado, Rodriquez e Püschel (2009).
} 
apresenta antes na qualidade de "contexto de surgimento" histórico e político de perspectivas normativas em disputa. Isso significa, portanto, que elucida de maneira peculiar uma vez que está ligado a um processo eminentemente prático - a gênese de categorias crítico-normativas.

Mas repensar a esfera pública implica também fazer com que tal conceito nos ajude na produção de diagnósticos de época. Testei sua aplicação nos casos em que a relação entre direito e política têm sido considerada da perspectiva de uma teoria crítica da democracia. Nesse caso, trata-se de reconstruir a esfera pública de acordo com os conflitos sociais que colocam em movimento uma dinâmica de democratização do sistema político. Utilizei assim a ideia de circulação do poder, empregada por Peters e Habermas, com a finalidade de enfatizar o conceito de esfera pública a partir dos processos que a compõem, considerando tanto seu centro multipolar quanto 34 estruturas periféricas e intermediárias (partidos, grupos de interesse, movimentos sociais etc.). Mas a atenção recai sobre como a pressão contida em tais processos é incorporada na esfera pública política (mídias de massa, opinião pública, redes diversas de comunicação, diferentes "públicos" cristalizados em torno de tópicos atuais e publicações, discussões específicas etc.) (cf. Peters, 2007c).

O recurso à circulação do poder, se buscar evitar um normativismo abstrato, não consiste certamente em neutralizar normativamente o processo que pretende ser compreendido. Ele mostra que o engessamento de contextos democráticos da vida produziu paradoxalmente uma luta por mais autonomia, por outras formas de organização social, pela democratização das instituições formais do sistema político. Por sua vez, como enfatiza Peters, preocupa-se em mostrar que, para além do quadro institucional, a vida democrática se espraia na periferia da sociedade, realizando-se em conjunto com uma cultura pública de fundo. 
Em suma, não se pode aferir adequadamente o sentido normativo dos processos de democratização caso o ponto de vista crítico não seja produzido de dentro da percepção das patologias e dos conflitos em questão. Mesmo porque, conforme mencionado antes, a própria esfera pública também se constituiu historicamente como fonte de opressão, injustiça e discriminação (contra mulheres, negros e outras minorias sociais e culturais). Logo, a circulação do poder nunca decide de antemão o sucesso ou a derrota das lutas sociais - já que, enquanto tal, a circulação do poder pode ou não ser democrática. Mas ela expõe a ambiguidade prática do conceito de esfera pública que uma teoria crítica da democracia tem de considerar, ainda que não se trate de resolvê-la em termos meramente teóricos, uma vez que remete às tendências emancipatórias - ou aos obstáculos à emancipação - a serem levadas a cabo pela práxis política autônoma dos próprios cidadãos.

\section{Rúrion Melo}

é professor do Departamento de Ciência Política da Universidade de São Paulo e pesquisador do Centro Brasileiro de Análise e Planejamento (Cebrap)

\section{Bibliografia}

ADORNO, T. W.; HORKHEIMER, M. 1985. Dialética do esclarecimento. Rio de Janeiro: Zahar.

ADORNO, T. W.; POLLOCK, F. 2011. Group experiment: the Frankfurt

School on public opinion in postwar Germany. Cambridge, MA:

Harvard University Press.

ARATO, A.; COHEN, J. 1991. Civil society and political theory. Cambridge,

MA: MIT Press.

ARENDT, H. 2009. A condição humana. Rio de Janeiro: Forense

Universitária.

BENHABIB, S. 1992a. "Models of public space: Hannah Arendt, the

liberal tradition and Jürgen Habermas". In: Situating the self. New

York: Routledge. 1992b. "The generalized and the concrete other". In:

Situating the self. New York: Routledge. 
1992c. "In the shadow of Aristotle and Hegel. Communicative ethics and current controversies in practical philosophy". In:

Situating the self. New York: Routledge. 2002. The claims of culture. Princeton: Princeton University Press.

BOHMAN, J. 1996. Public deliberation. Cambridge, MA: MIT Press. 2007. Democracy across borders. Cambridge, MA: MIT Press.

CALHOUN, C. 1982. The question of class struggle. Social foundations of popular radicalism in industrial England. Chicago: The University of Chicago Press.

2012. The roots of radicalism. Tradition, the public sphere, and Early

Nineteenth Century social movements. Chicago: The University of Chicago Press.

CALHOUN, C. (ed.). 1992. Habermas and the public sphere. Cambridge, MA: MIT Press.

CELIKATES, R. 2009. Kritik als soziale Praxis: Gesellschaftlische Selbstverständigung und kritische Theorie. Frankfurt am Main: Campus Verlag.

COSTA, S.; MELO, R.; SILVA, F. G. 2009. "Sociedad civil, Estado y derecho em América Latina: tres modelos interpretativos”. In: ARAUJO,

K. (org.). ¿Se acata pero no se cumple? Estudios sobre las normas em América Latina. Santiago: LOM.

COSTA, S. et al. (2011). "Para além da inefetividade da lei: Estado de direito, esfera pública e antirracismo" In: LAVALLE, A. G. (org.). O horizonte da política: questões emergentes e agendas de pesquisa. São Paulo: Ed. Unesp.

DEWEY, J. 1954. The public and its problems. Chicago: The University of Chicago Press.

DORESKI, C. K. (ed.). 1999. Writing American Black: race rhetoric and the public sphere. Cambridge: Cambridge University Press.

FORST, R. 2010. Contextos da justiça. São Paulo: Boitempo.

FRASER, N. 1989. "What's critical about critical theory? The case of Habermas and gender". In: FRASER, N. Unruly practices. Minneapolis: University of Minnesota Press.

1992. "Rethinking the public sphere: a contribution to the critique of actually existing democracy". In: CALHOUN, C. (ed.). Habermas and the public sphere. Cambridge, MA: MIT Press.

2010. "Transnationalizing the public sphere: on the legitimacy and efficacy of public opinion in a Postwetphalian world”. In: . Scales of justice. New York: Columbia University Press.

. 2013. "Between marketization and social protection: resolving the feminist ambivalence". In: FRASER, N. Fortunes of feminism. London/ New York: Verso. 
GRISPRUD, J. et al. (ed.). 2010. The idea of the public sphere: a reader.

Lanham, Maryland: Lexington Books.

HABERMAS, J. 1961. Student und Politik. Neuwied/Berlin: Luchterhand. . 1981. Theorie des kommunikativen Handelns. Frankfurt am Main:

Suhrkamp. 2 v. 1994. Faktizität und Geltung. Frankfurt am Main: Suhrkamp. 1997. Die Einbeziehung des Anderen. Frankfurt am Main: Suhrkamp. 2005. Zwischen Naturalismus und Religion. Frankfurt am Main:

Suhrkamp. . 2008. Ach, Europa. Frankfurt am Main: Suhrkamp. 2013. Teoria e práxis. São Paulo: Ed. Unesp.

. 2014 [1962]. Mudança estrutural da esfera pública. São Paulo: Ed. Unesp.

HONNETH, A. 1985. Kritik der Macht. Frankfurt am Main: Suhrkamp. 2000a. "Demokratie als reflexive Kooperation. John Dewey und die Demokratietheorie der Gegenwart". In: . Das Andere der

Gerechtigkeit. Frankfurt am Main: Suhrkamp. . 2000b. "Die soziale Dynamik von Missachtung. Zur Ortbestimmung einer kritischen Gesellschaftstheorie”. In: . Das Andere der

Gerechtigkeit. Frankfurt am Main: Suhrkamp. 2003. Luta por reconhecimento: a gramática moral dos conflitos sociais. Trad. Luiz Repa. São Paulo: Ed. 34. 2011. Das Recht der Freiheit. Berlin: Suhrkamp.

JAEGGI, R. 2013. Kritik von Lebensformen. Berlin: Suhrkamp.

KEANE, J. 1988. Democracy and civil society: on the predicaments of European Socialism, the prospects for democracy, and the problem of controlling social and political power. London: University of Westminster Press.

KLUGE, A.; NEGT, O. 1993. Public sphere and experience. Toward an analysis of the bourgeois and proletarian public sphere. Minneapolis: University of Minnesota Press.

LANG, S. 2014. NGOs, Civil society, and the public sphere. Cambridge: Cambridge University Press.

LAVALLE, A. 2003. A. "Sem pena nem glória: O debate da sociedade civil nos anos 1990”. Novos Estudos Cebrap, n. 66.

LAVALLE, A.; CASTELLO, G.; HOUTZAGER, P. P. 2011. “A construção política das sociedades civis”. In: LAVALLE, A. G. (org.). O horizonte da política: questões emergentes e agendas de pesquisa. São Paulo: Ed. Unesp.

LIPPMANN, W. 1993. The phantom public. New Brunswick: Transaction Publisher. 2012. Public opinion. New York: The Free Press. 
LOPES, J. S. L.; HEREDIA, B. M. A. (orgs.). 2014. Movimentos sociais e esfera pública: o mundo da participação. Rio de Janeiro: Ed. UFRJ.

MACHADO, M.; RODRIGUEZ, J. R.; PÜSCHEL, F. 2009. "The juridification of social demands and the aplication of the statutes: An analisys of the legal treatment of antiracism social demands in Brazil". Fordham Law Review, n. 77.

. 2011. "A democratização do direito: os dilemas da juridização e o racismo no Brasil”, In: LAVALLE, A. G. (org.). O horizonte da política: questões emergentes e agendas de pesquisa. São Paulo: Ed. Unesp.

MACHADO, M. et al. 2013. "Disputando a aplicação das leis: a constitucionalidade da Lei Maria da Penha nos tribunais brasileiros". Revista Internacional de Direitos Humanos, n. 9.

MCCARTHY, T. 1991. "Practical discourse: on the relation of morality to politics". In: Ideals and illusions. Cambridge, MA: MIT Press.

MEEHAN, J. (ed.). 1995. Feminists read Habermas. London: Routledge.

MELO, R. 2011. O uso público da razão: pluralismo e democracia em Jürgen Habermas. São Paulo: Loyola. 2013. Marx e Habermas: teoria crítica e os sentidos da emancipação. São Paulo: Saraiva. 2014. "Da teoria à práxis? Axel Honneth e as lutas por reconhecimento na teoria política contemporânea”. Revista Brasileira de Ciência Política, n. 15.

MELO, R.; SILVA, F. G. 2012. "Crítica e reconstrução em Direito e democracia”. In: NOBRE, M.: REPA, L. (orgs.). Habermas e a reconstrução. Campinas, SP: Papirus.

MILLS, C. W. 2000. The power elite. Oxford: Oxford University Press. NIESEN, P.; HERBORTH, B. (Hg.). 2007. Anarchie der kommunikativen Freiheit. Jürgen Habermas und die Theorie der internationalen Politik. Frankfurt am Main: Suhrkamp.

NOBRE, M.; REPA, L. (orgs.). 2012. Habermas e a reconstrução. Campinas, SP: Papirus.

O’NEIL, O. 1990. Constructions of reason. Cambridge: Cambridge University Press. PETERS, B. 1992. Die Integration moderner Gesellschaften. Frankfurt am Main: Suhrkamp. . 2007a. Der Sinn von Öffentlichkeit. Frankfurt am Main: Suhrkamp. 2007b. "Der Sinn von Öffentlichkeit". In: . Der Sinn von

Öffentlichkeit. Frankfurt am Main: Suhrkamp. . 2007c. "Über öffentliche Deliberation und öffentliche Kultur".

In:___ Der Sinn von Öffentlichkeit. Frankfurt am Main: Suhrkamp. . 2007d. "Nationale und transnationale Öffentlichkeiten - eine 
Problemskizze". In: PETERS, B. Der Sinn von Öffentlichkeit. Frankfurt am Main: Suhrkamp.

PETERS, B. et al. (eds.). 2009. Transnationalization of public spheres.

Basingstoke: Palgrave Macmillan.

RAWLS, J. 2007. "A ideia de razão pública revisitada”. In: MELO, R.;

WERLE, D. L. (orgs.). Democracia deliberativa. São Paulo: Esfera Pública. 2011. O liberalismo político. São Paulo: Martins Fontes.

RODRIGUEZ, J. R.; SILVA, F. G. (orgs.). 2013. Manual de sociologia jurídica. São Paulo: Saraiva.

SCHEUERMAN, W. 2002. "Between radicalism and resignation:

democratic theory in Habermas's between facts and norms". In: BAYNES, K.; VON SWCHOMBERG, R. (eds.). Dicourse and democracy: essays on Habermas's between facts and norms. New York: New York University Press.

STRUM, A. 1994. "A bibliography of the concept Öffentlichkeit". New German Critique, n. 61.

TAYLOR, C. 2000. "A política liberal e a esfera pública”. In:

Argumentos filosóficos. São Paulo: Loyola.

THOMPSON, E. P. 1993. Customs in common. New York: New Press. . 2002. A formação da classe operária inglesa. São Paulo: Paz e Terra. 3 v.

THOMPSON, J. B. 1990. Ideology and modern culture. Stanford: Stanford

University Press. 1995. The media and modernity: a social theory of the media.

Stanford: Stanford University Press.

WALZER, M. 2007. "Deliberação, e o que mais?”. In: MELO, R.; WERLE,

D. L. (orgs.) Democracia deliberativa. São Paulo: Esfera Pública.

YOUNG, I. 1990. Justice and the politics of difference. Princeton: Princeton

University Press. 


\section{REPENSANDO A ESFERA PÚBLICA: ESBOÇO DE UMA TEORIA CRÍTICA DA DEMOCRACIA}

RÚRION MELO

Resumo: $O$ artigo procura repensar o conceito de esfera pública em dois níveis de reconstrução. Em primeiro lugar, compreendemos a esfera pública não em termos puramente normativos, mas como ponto de partida socialmente constituído para a reconstrução de categorias críticas. Em segundo lugar, mantendo a preocupação metodológica com a gênese prática do conceito, mostramos de que maneira o conceito de esfera pública pode ser reconstruído como um processo de circulação do poder, que nos permite diagnosticar criticamente as relações atuais entre política e direito, mais especificamente a democratização do sistema político colocada em marcha pelos conflitos sociais.

Palavras-chave: Esfera Pública; Democracia; Teoria Crítica; Circulação do Poder; Habermas.

\section{RETHINKING THE PUBLIC SPHERE: SKETCH OF A CRITICAL THEORY OF DEMOCRACY}

Abstract: The article seeks to rethink the concept of public sphere in two levels of reconstruction. First, we understand the public sphere not in purely normative terms, but as a socially constituted point of departure for the reconstruction of critical categories. Secondly, keeping the methodological concern with the practical genesis of the concept, we show how the concept of public sphere can be reconstructed as a process of circulation of power that allows us to critically diagnose the current relationship between politics and law, specifically the democratization of the political system putted in motion by social conflicts.

Keywords: Public Sphere; Democracy; Critical Theory; Circulation of Power; Habermas.

Recebido: 12/10/2014

Aprovado: 20/02/2015 